\title{
USE OF NON-DEGENERATE HUMAN OSTEOCHONDRAL TISSUE AND CONFOCAL LASER SCANNING MICROSCOPY FOR THE STUDY OF CHONDROCYTE DEATH AT CARTILAGE SURGERY
}

\author{
J.S. Huntley ${ }^{1 *}$, A.H. Simpson ${ }^{1}$ and A.C. Hall ${ }^{2}$ \\ ${ }^{1}$ Musculoskeletal Research Unit, School of Clinical and Surgical Sciences, ${ }^{2}$ School of Biomedical and Clinical \\ Laboratory Sciences, University of Edinburgh, Edinburgh, U.K.
}

\begin{abstract}
Although autologous osteochondral grafting has been widely applied in humans, most in vitro work has been on animal models. The aims of this study were to: (i) elaborate a full thickness human femoral condylar model using discard material from knee arthroplasty resections, and (ii) use this model to assess chondrocyte viability in response to surgical trauma.

Homogeneous regions of human lateral femoral condyle bone-cartilage were procured from knee arthroplasty resections. These were graded prospectively, firstly by visual inspection, and then by confocal laser scanning microscopy (CLSM). Samples were subjected to tests of tissue hydration, including analysis of water content and swelling after excision from underlying bone. Surgical cuts were made in explants that were macroscopically and microscopically normal (i.e. Grade 0). Associated margins of death were assessed from both transverse and surface perspectives.
\end{abstract}

Thirty-nine samples were obtained from anterior and distal femoral cuts (16 knees from 13 patients) for (1) macroscopic grading, (2) microscopic analysis, (3) analyses of water content as cut and on re-equilibration after excision from bone. Thirteen were Grade 0 on macroscopic viewing - however one showed fibrillation on microscopy and was therefore reassigned Grade 1 . Grade 0 tissue had a water content of $73.8 \pm 0.38 \%$, in agreement with control values from the literature. Tissues of Grades 2 and 3 were significantly $(\mathrm{P}=0.03$, and $\mathrm{P}=0.004)$ more hydrated $(76.0 \pm 0.59 \%, 76.7 \pm 0.99 \%)$ than Grade 0 tissue. Grade 0 tissue from the anterior cut did not swell significantly following excision from subchondral bone. However Grade 0 tissue from the distal cut showed a small but statistically significant $(\mathrm{P}=0.019)$ increase in water content $(1.68 \pm 0.39 \%)$ following excision. With increasing grade there was increased tendency to swell off the bone $(\mathrm{P}<0.0001)$. Transverse imaging showed that the Acufex MP surgical harvester caused a greater margin of cell death $(211 \pm 18.3 \mu \mathrm{m})$ in the superficial zone (SZ) than the midzone $(50.5 \pm 13.6 \mu \mathrm{m} ; \mathrm{P}=0.022)$, or $\mathrm{SZ}$ death from a scalpel cut (33.0 $\pm 8.5 \mu \mathrm{m} ; \mathrm{P}=0.0009)$. Similarly, in unfixed samples viewed from the surface perspective, the margin of death for the surgical harvester $(277 \pm 7.2 \mu \mathrm{m})$ was significantly $(\mathrm{P}<0.0001)$ greater than that for the scalpel $(38.8 \pm 7.2 \mu \mathrm{m})$.

If macroscopically and microscopically non-degenerate, then human lateral femoral condylar cartilage from the anterior cut of knee resections has normal biophysical parameters (water content and lack of swelling on excision). The surgical harvester (Acufex), used in human osteochondral grafting, caused a substantial margin of cell death at the periphery of the graft, and the SZ appeared to be especially vulnerable. This effect may be important in terms of limiting the reparative capacity of the SZ. The harmful effect on viability is likely to impede lateral repair which is fundamental to subsequent structural and functional integrity.

Key Words: Autologous osteochondral grafting, human cartilage, chondrocyte, articular surgery, cell death.

*Address for correspondence:

J.S. Huntley

Musculoskeletal Research Unit,

School of Clinical and Surgical Sciences,

University of Edinburgh,

Teviot Place,

Edinburgh EH8 9AG

Telephone Number: +44-131-6502948

FAX Number: +44-131-6513077

E-mail: jimhuntley@doctors.net.uk

\section{Introduction}

Bone-cartilage composite grafting of articular defects has a long history (Lexer 1908, 1925; Volkov, 1970; Czitrom et al., 1990; Aubin et al., 2001). In the last decade, autologous osteochondral grafting (mosaicplasty) has become a popular and widespread treatment option for smaller articular defects (Bentley et al., 2003; Hangody and Fules, 2003; Horas et al., 2003; Hangody et al., 2004). In this procedure, osteochondral cylinders are transposed from a region of lower demand into the defect (Hangody et al., 2004). The long-term fate of joints subjected to this procedure is not known, and only early results comparing the technique with other strategies are available (Bentley et al., 2003; Horas et al., 2003). These studies have somewhat conflicting conclusions. Bentley et al. (2003) documented superior results for autologous chondrocyte implantation (ACI) - however the mean defect size was large $\left(4.66 \mathrm{~cm}^{2}\right)$, and greater than the maximum currently suggested for mosaicplasty $\left(4 \mathrm{~cm}^{2}\right)$. The second study was more equivocal and suggested that fibrocartilage was the predominant repair tissue in ACI (Horas et al., 2003).

At present, there are several major reservations concerning osteochondral grafting, including (1) a lack of lateral integration, (2) inferior load-bearing qualities of the tissue bridging the graft-graft and graft-recipient sites, and (3) donor site morbidity. Cartilage has a complex three-dimensional arrangement of interlacing collagen 
fibres (Jeffery et al., 1991) in which the superficial zone contains tightly packed collagen fibrils which are aligned parallel to the joint surface, in the form of a tough 'rind' (Poole, 2003). The surface, functioning as a syncitium, is a 'tension-resisting diaphragm' (Meachim and Stockwell, 1973) without a natural plane of cleavage. Damage to this zone results in early fibrillation which progresses to the deeper zones (Poole, 2003). 'Repair' tissue has different mechanical properties to those of the neighbouring pristine cartilage, such that on joint loading there are large gradients in tissue displacement and stress across the repair:normal interface (Ahsan and Sah, 1999). In rabbits, the extended natural history of repair of full thickness defects (with penetration of the bone; and no graft) has been documented, with encouraging histological results at 8 weeks (Shapiro et al., 1993). Subsequently (by 48 weeks), however, there was usually degeneration (Shapiro et al., 1993). It is a concern that signs of early degeneration in the superficial zone can also be found in many cases of apparently 'successful' human cartilage repair (Poole, 2003).

Surgical wounding of cartilage is well known to cause chondrocyte death near the cut edge (Stockwell, 1979; Hunziker and Quinn, 2003; Redman et al., 2004). Adequate cellularity near the graft and recipient edges is thought to be an important determinant of the quality of repair, and the longevity of the composite construct (Bos et al., 2002). Failure of cartilage integration (Reindel et al., 1995; DiMicco and Sah, 2001) may be due to cell death at the margin of grafts. Recently Evans et al. (2004) used an ovine model to compare the effects of two modes of harvest (power trephine and punch) on chondrocyte viability. Although there was a clear difference between the groups, it was also noted that the ovine sytem was hard to use and the subchondral bone very stiff compared to humans. Indeed, most of the in vitro experimental work on cartilage wounding and integrative repair has been performed on animal models. The properties of such systems are substantially different from their human equivalent, and thus there are difficulties in extrapolating inferences to the human situation (Roach et al., 1989).

Conversely, in the in vivo situation, Hunziker (2001) states: 'It is a disturbing finding that this intervention has been applied in human patients before having been thoroughly tested in animal investigations, particularly long-term ones which would reveal whether any associated joint pathologies develop'. Given the widespread application of osteochondral grafting in humans, it seems desirable to gain additional insight into the effects of surgery, and processes of marginal cell death and integrative repair in an in vitro human model. However pristine human tissues are in short supply and there are obstacles to obtaining post-mortem tissues for research activities (Nicholson, 2004). A further impediment to using human tissue is the availability of truly non-compromised tissue for comparison (Roach et al., 1989). With the appropriate reservations, one pragmatic approach has been to compare degenerate and non-degenerate regions of the same joint (Bush and Hall, 2003).

We therefore used macroscopically non-degenerate cartilage from human knee resections for osteoarthritis.
A

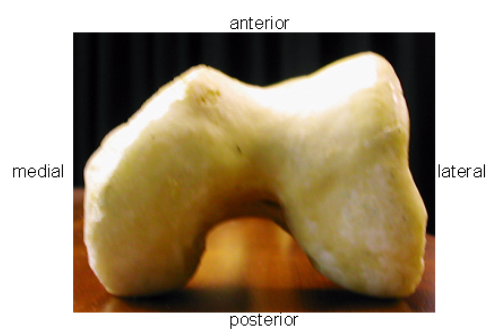

B

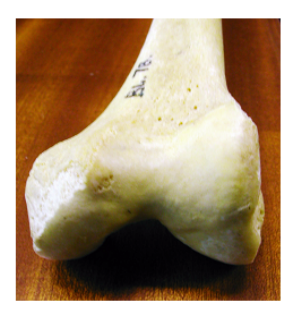

Figure 1. Photographs of dry bones showing the anatomy of the distal femur [Anatomy Department, University of Edinburgh]. (A) End-on view. (B) Oblique view. Note the anterior prominence of the lateral femoral condyle.
A

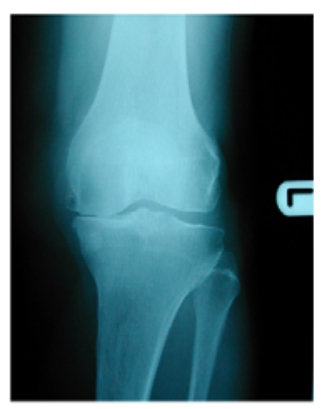

B

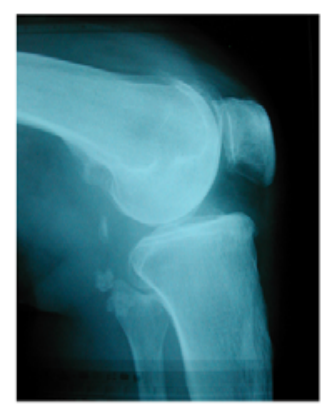

Figure 2. Anterior (A) and lateral (B) radiographs of the left knee of a 63 year-old female patient with bilateral knee osteoarthritis. The medial compartment has been affected preferentially - and exhibits the characteristic radiographic changes of narrowed joint space, bony sclerosis, osteophyte formation and cystic change.

The rationale underlying this proposition comes partly from evidence documenting the strong similarity between this tissue and pristine cartilage (Brocklehurst et al., 1984). It is a feature of distal femoral anatomy that the lateral condyle has a more prominent antero-superior portion than the corresponding medial condyle (Fig. 1). Furthermore osteoarthritis of the knee tends to affect the medial compartment preferentially to the lateral (Fig. 2) i.e., a varus deformity is more common than a valgus one (Hulet et al., 2002). Knee arthroplasty involves jig-based cuts of the distal femur and it is desirable to site the femoral component in slight external rotation with respect to the transepicondylar axis (Engh, 2000; Scuderi and Insall, 2000). Thus the anterior cut at knee arthroplasty usually removes a more substantial portion of bone-cartilage from the lateral (as opposed to medial) femoral condyle. This region is also one of the recommended harvest sites for mosaicplasty (Hangody et al., 2004).

In the unloaded situation, the water content of mature human hip and knee cartilage is a function of the tensile properties of the collagen network and the proteoglycan content (Maroudas, 1990). When healthy, these adult human tissues have a stiff collagen network such that they have little tendency to swell, in contrast to young bovine knee cartilage (Maroudas, 1990). However osteoarthritic human cartilage swells on excision, which is attributed to 
damage in the surrounding collagen network (Maroudas, 1976, 1990).

We conjectured that lateral condylar regions of resection specimens from patients undergoing total knee replacement for osteoarthritis (OA) might constitute similar material to that encountered at osteochondral grafting, and therefore be relevant to test osteoarticular harvest techniques. For the study of the response of in situ human chondrocytes to wounding, confocal laser scanning microscopy (CLSM) has several advantages over conventional histology. Firstly, it avoids artefacts of sectioning and fixation. It also allows three-dimensional visualisation of living cells within their native extracellular environment, and live/dead quantification (Bush and Hall, 2003).

The aims of this study were to determine (1) if macroscopically non-degenerate lateral human condylar tissue could be used to assess the effects of surgical harvest on graft edge viability by characterising the elementary biophysical (water content and swelling on excision) and microscopic (CLSM) parameters, and (2) the effects of surgically relevant cuts, by comparing scalpel (number 11 blade) and the Acufex MP osteotome.

\section{Materials and Methods}

\section{Ethical approval}

Approval was granted by Fife Acute Hospitals NHS Trust (Scotland) Ethics Committee. Informed consent was obtained from patients undergoing total knee replacement.

\section{Biochemicals}

Biochemicals were from Sigma (Poole, Dorset, UK) apart from: (1) fluorescent indicators 5-chloromethylfluoroscein diacetate (CMFDA) and propidium iodide (PI) from Molecular Probes (Eugene, Oregon, USA), and (2) formaldehyde solution ( $10 \% \mathrm{v} / \mathrm{v}$ in normal saline; $\mathrm{pH} 7.3)$ from Fisher Scientific (Leicestershire, UK). Stock solutions were PI (1 mM; aqueous) and CMFDA (2.15 mM; dimethyl sulphoxide (DMSO)). The culture medium was Dulbecco's modified Eagle's medium (DMEM; serum-free) with N-2hydroxyethylpiperazine-N'-2-ethanesulphonic acid (HEPES) at $25 \mathrm{mM}$, and $\mathrm{pH}$ 7.4.

\section{Human osteochondral explants}

Resection specimens from total knee arthroplasties for osteoarthritis were placed immediately into DMEM and refrigerated at $4^{\circ} \mathrm{C}$ (Aubin et al., 2001). Samples were used within 24 hours for experiments involving surgical cuts, and 48 hours for analyses of water content and swelling following excision. Both anterior and distal femoral resection cuts (Fig. 3) were used as a source for lateral condylar osteochondral explants - initial osteochondral blocks were trimmed out using a toffee hammer and Stanley knife.

\section{Tissue hydration experiments}

Regions of cartilage were selected that appeared macroscopically homogeneous over an area of at least $7 \mathrm{~mm}$ $\mathrm{x} 7 \mathrm{~mm}$. Using aseptic technique, osteochondral cuboids of this surface dimension were harvested using fresh scalpel

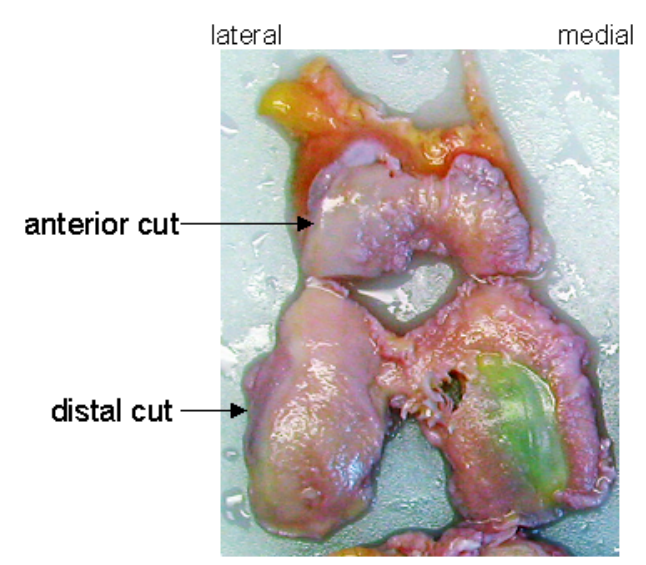

Figure 3. Femoral condyle resection specimens (anterior and distal cuts) from total knee arthroplasty. Note the changes of osteoarthritis preferentially affecting the medial side.

A

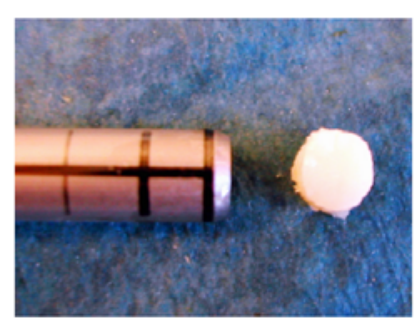

B

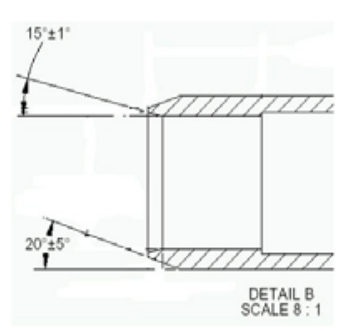

Figure 4. Smith \& Nephew Acufex MP (4.5mm diameter) osteotome. (A) Photograph with harvested osteochondral plug viewed end-on. (B) Crosssectional diagram.

blades for each cut to minimise disruption near the edge. These cuboids were graded prospectively using the International Cartilage Repair Society (ICRS) system (ICRS, 2000; see below). The surface was maintained wet with DMEM throughout, to avoid the deleterious effects of drying (Mitchell and Shepherd, 1989). An approximately $200 \mu \mathrm{m}$ portion was shaved off the edge of each cuboid, such that the full thickness of cartilage and subchondral bone could be imaged from a transverse perspective. The remaining tissue was analysed for (1) water content, and (2) changes to tissue hydration when excised from the subchondral bone.

Cartilage was excised from bone and blotted to remove excess surface fluid. The sample was weighed as cut before being transferred to DMEM for 30 minutes, and weighed again, to assess swelling attributable after excision. The sample was dried to completion (after 6 hours, further drying caused no decrease in weight) in an oven at $60^{\circ} \mathrm{C}$, and reweighed.

The initial water content (\%) was calculated as: $100 \%$ x $\{$ (wet weight-dry weight)/(wet weight) $\}$

The percentage change (\%) in wet weight after excision was calculated as:

$100 \% \times$ [ $\{$ (wet weight 30 mins after excision)/(wet weight as cut) $\}-1]$ 


\section{Harvest/wounding procedures}

The circular Acufex MP (4.5mm internal diameter; Fig. 4A; scale-drawing Fig. 4B; courtesy of Smith \& Nephew, London, U.K.) was used to make cuts in cartilage explants within 24 hours of the original arthroplasty operation. The osteotome was applied perpendicular to the articular surface, and a light toffee hammer (230 g) used to deepen the cut to either (1) harvest a bone-cartilage composite plug of 7-9 mm length, or (2) cut as far as subchondral bone before retraction (leaving the plug in situ and attached to subchondral bone). No rotational movement was made. Scalpel cuts (No. 11 blade) were also made in push-through mode, with force applied solely perpendicular to the articular surface. Care was taken not to subject the cartilage to any additional trauma, other than that of the harvesting procedure. Because of concerns over blade sharpness, we used only virgin scalpel blades, and no Acufex was used more than 6 times (i.e., well within the operational limit).

\section{Fluorescent dyes}

Fluorescent dyes have been used to document cell viability/ death (Mainil-Varlet et al., 2001; Bush and Hall, 2003). CMFDA is membrane-permeant, and cleaved by intracellular esterases to produce a fluorescent and membrane-impermeant product. The cytoplasm of viable cells is labelled green. Conversely, PI is a charged molecule, capable of crossing damaged cell membranes, and staining the nuclei of dead cells red. Tissue was incubated with dye concentrations of $21.5 \mu \mathrm{M}$ (CMFDA) and $5 \mu \mathrm{M}(\mathrm{PI})$, to optimise imaging parameters.

\section{Confocal laser scanning microscopy (CLSM)}

An upright Zeiss Axioskop LSM510 (Carl Zeiss UK, Welwyn Garden City, Hertfordshire, U.K.) (x10 dry objective) was used to acquire images of in situ labelled articular chondrocytes. Wavelengths $\left(\mathrm{EX}_{\lambda}\right)$ of 488 and 543 $\mathrm{nm}$ were used to excite CMFDA and PI, respectively. Using a 'multi-track' protocol, which involved alternate excitation/visualisation of the two dyes, fluorescence emissions from CMFDA (staining cytoplasm for live cells; green) and PI (nuclear staining of dead cells; red) were quantified separately. Bandpass and long pass filters were employed to measure emission $(500-550 \mathrm{~nm}$ and $>560 \mathrm{~nm}$, respectively). Cartilage was viewed from both transverse and superficial perspectives, according to the experiment (see Figure legends). Laser power, detector gain and sensitivity were adjusted to avoid excessive bleaching and saturation. Optical sections were obtained at approximately $10 \mu \mathrm{m}$ intervals, over a depth of $170 \mu \mathrm{m}$.

\section{Tissue grading}

There are several classification systems available for grading articular cartilage lesions, which suffer from a variety of limitations and deficiencies (Mankin et al., 1971; Noyes and Stabler, 1989). The Collins and McElligott system (Collins, 1949; Collins and McElligott, 1960) has often been applied focally (Millward-Sadler et al., 1998; Bush and Hall, 2003), even though it is a pan-joint classification. In its focal form the Collins and McElligott system approximates to the ICRS Grading system (ICRS,

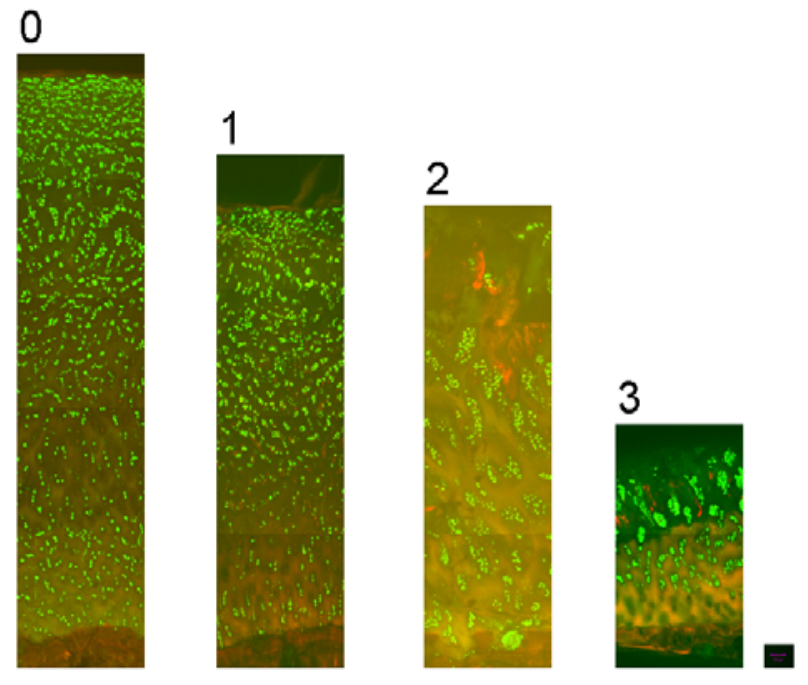

Figure 5. Human femoral articular cartilage morphology as a function of cartilage grade. Representative projectional images of grades 0-3 obtained by CLSM (aprroximately $170 \mu \mathrm{m}$ depth). Chondrocytes are labelled green (live) and red (dead) with CMFDA and PI (respectively), with highlighting of the extracellular tissue-staining/autofluorescence to highlight erosive changes. There is progressive architectural damage and erosive change across Grades (0-3), with cellular clustering in Grades 2-3. Scale bar $100 \mu \mathrm{m}$.
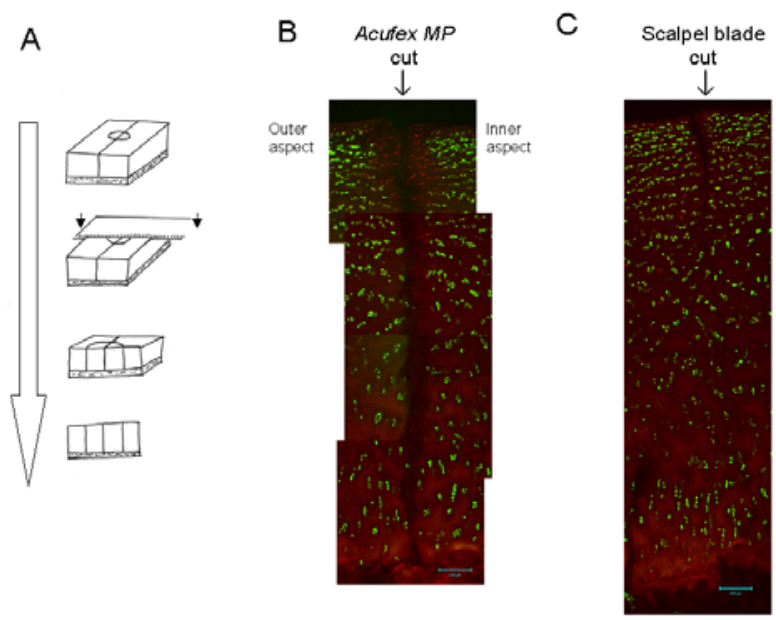

Figure 6. Comparison of Acufex MP and scalpel cuts on osteochondral explants without breach of the subchondral bone. Transverse projectional views (170 $\mu \mathrm{m}$ depth) showing full thickness of cartilage (about $3.5 \mathrm{~mm}$ ), with Acufex MP and scalpel cuts to subchondral bone before the instrument was gently retracted (A). After cutting, explants were incubated for 2 hours with dye exposure for the last 30mins, before fixation in 10\% formal-saline (see Materials and Methods). Panels show the associated margins of cell death (red) for the two cuts. The zone of death is most extensive for the Acufex MP (B) in the superficial zone, and significantly greater than that associated with the scalpel cut (C) to the same depth. Scale bar 200 $\mu \mathrm{m}$. 
2000; Mainil-Varlet et al., 2003) - which has been used here to grade tissue prospectively: Grade 0 (normal), Grade 1 (nearly normal - superficial lesions only), Grade 2 (abnormal - lesions extending down to $<50 \%$ cartilage depth), Grade 3 (severely abnormal - lesions extending down to $>50 \%$ cartilage depth), and Grade 4 (severely abnormal, abrading bone).

Each lateral condylar cartilage sample (taken from either anterior or distal cuts and graded prospectively) was then subjected to microscopic transverse sectional imaging by CLSM (x10 objective) across the complete depth. All samples were assessed using the following criteria: (1) intact surface (yes/no) - using contrast/brightness adjustment to show fibrillation or splitting from extracellular matrix autofluorescence and tissue staining, (2) the presence/absence of a well-defined superficial zone (yes/no) - on the basis of cell distribution and overall arrangement, (3) Cell distribution - the presence/absence of clustering/columns (Graded 0-3; Mainil-Varlet et al., 2003), (4) if a defect across the superficial zone was present, the extent it reached (mid-zone (MZ)/deep-zone (DZ)) - analagous to the 'Structure' component of the Histological-Histochemical grading of Mankin et al. (1971), and (5) cell viability (\%).

\section{Incubation and fixation}

For most experiments (Figs. 5 and 6), samples were incubated at $37^{\circ} \mathrm{C}$ for $120 \mathrm{mins}$, incorporating exposure to PI $(5 \mu \mathrm{M})$ and CMFDA $(21.5 \mu \mathrm{M})$ for the final 30 mins. At the end of the incubation period, plugs were washed in DMEM and transferred to formal-saline $(10 \% \mathrm{v} / \mathrm{v})$. They were stored at $4^{\circ} \mathrm{C}$ and, after passage to ethanol $(70 \% \mathrm{v} / \mathrm{v})$, were analysed in water, at $21^{\circ} \mathrm{C}$, on the subsequent day. However for experiments in which microscopy was performed on unfixed tissue (Fig. 7), exposure to PI (5 $\mu \mathrm{M})$ and CMFDA $(21.5 \mu \mathrm{M})$ occured in DMEM at $37^{\circ} \mathrm{C}$ for 15 mins before incisions were made. Samples were then transferred to CLSM, and maintained in DMEM, with dyes at the same concentration, at $21^{\circ} \mathrm{C}$ over 2 hours, prior to imaging living tissue at the junction of scalpel and Acufex cuts.

\section{Post acquisition analysis}

The Zeiss Image Browser was used (1) for image overlay and projection, and (2) for area and distance assessments where appropriate. Average margins of death were derived using an area method (Chen et al., 2003), calculating the ratio of the total area (of dead cells) to the length of cut surface. In transverse section tissue was designated as belonging to the superficial zone, mid-zone or deep zone on the basis of, (1) cellular arrangement (reflecting tissue architecture), (2) cell density, and (3) distance from the articular surface (Bush and Hall, 2003). When the margin of death was for a curved surface (Acufex MP cuts from above) the average margin was derived using a similar method (see Appendix; Figure 8), with measurements of the perimeter (Browser), and plug diameter (using Vernier calipers; British Aerospace, London, U.K.; accuracy 10 $\mu \mathrm{m})$.
Table 1. Human lateral femoral condylar cartilage hydration by grade - initial values and following excision from subchondral bone.

\begin{tabular}{lllllll}
\hline & $0-$ & $0-$ & $1-$ & $1-$ & $2-$ & $3-$ \\
& $\begin{array}{l}\text { anterior } \\
(6)\end{array}$ & $\begin{array}{l}\text { distal } \\
(6)\end{array}$ & $\begin{array}{l}\text { anterior } \\
(6)\end{array}$ & $\begin{array}{l}\text { distal } \\
(7)\end{array}$ & $\begin{array}{l}\text { pooled } \\
(9)\end{array}$ & $\begin{array}{l}\text { pooled } \\
(5)\end{array}$ \\
\hline $\begin{array}{l}\text { water content } \\
(\%)\end{array}$ & $73.9 \pm$ & $73.7 \pm$ & $73.1 \pm$ & $73.7 \pm$ & $76.0 \pm$ & $76.7 \pm$ \\
\% increase & 0.63 & 0.48 & 0.69 & 1.47 & 0.59 & 0.99 \\
(excision) & $0.35 \pm$ & $1.68 \pm$ & $4.16 \pm$ & $4.03 \pm$ & $5.31 \pm$ & $11.7 \pm$ \\
& 0.27 & 0.39 & 1.27 & 0.83 & 1.50 & 1.67 \\
\hline
\end{tabular}

Cartilage was graded as described (see Methods and Results), excised from the subchondral bone and weighed 'as cut'. Samples were then placed in DMEM (280 mOsm) for 30 mins before being re-weighed (final wet weight). Samples were then dried to completion and reweighed (dry weight). Water content (\%) and \% increase on excision were calculated from these three measurements (see Methods). For elaboration of statistically significant findings see Results.

\section{Statistics}

Data are given as mean \pm SEM. Differences between the means of two groups were determined using Student's unpaired $t$-tests. Trends across grades were assessed using analysis-of-variance (ANOVA). Significance was determined at $\alpha=0.05$, for analyses performed using GraphPad (San Diego, CA, USA) Prism 4.0 software.

\section{Results}

\section{Tissue grading and biophysical analysis}

Thirty-nine lateral condylar samples were taken from the anterior and distal femoral cuts of 16 knee arthroplasty resections for osteoarthritis (13 patients; 3 bilateral; 7 men, 6 women; age $68.4 \pm 2.9$ (range $41-82$ ) years). Thirteen samples were Grade 0, macroscopically non-degenerate ( 7 from anterior cuts; 6 from distal cuts). Figure 5 shows low power CLSM projected transverse sectional images of cartilage, representative of Grades 0-3, showing the relation of grade to fibrillation, degeneration and cell clustering. It was important to exclude samples with early degenerative change from the apparently Grade 0 (macroscopically non-degenerate) group. Microscopic analysis of tissue sections of macroscopically assessed Grade 0 tissue $(n=13)$ showed only 1 sample (from the anterior cut group) as having surface fibrillation - which was therefore re-assigned as Grade 1. Accordingly 12 Grade 0 samples remained (6 samples from each of anterior and distal cuts).

Table 1 shows data of initial water content of cartilage and the $\%$ increase in wet weight on excision from bone. Interestingly there was no significant difference in water content between Grade 0 and Grade 1 tissue. However, Grades 2 and 3 showed a significantly $(\mathrm{P}=0.03, \mathrm{P}=0.004$, respectively) greater initial water contents $(76.0 \pm 0.59 \%$, 
A

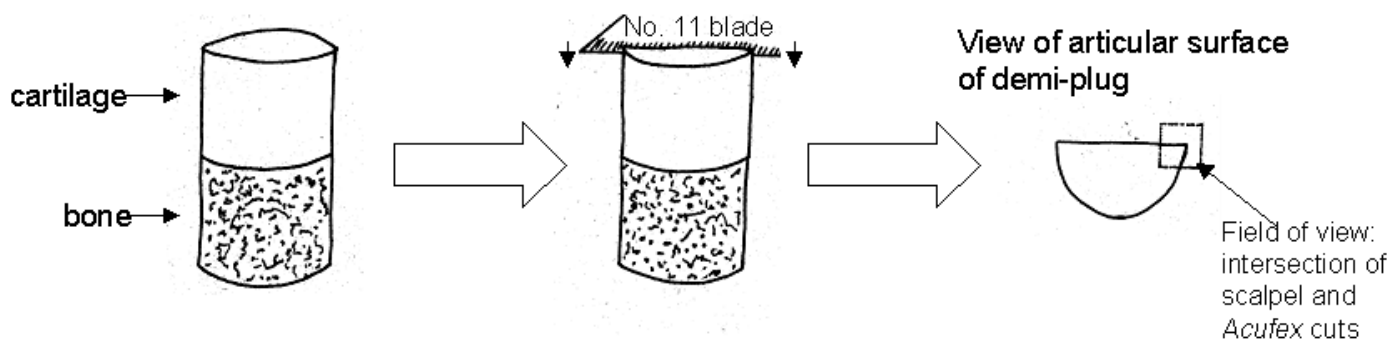

B

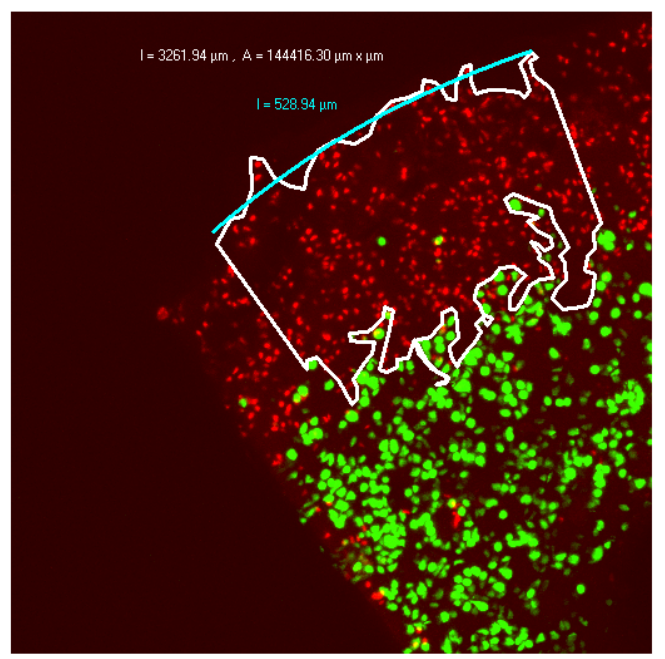

Figure 7. Early marginal zone cell death. (A) Osteochondral explants in DMEM were incubated with CMFDA and PI for 15 mins at $37^{\circ} \mathrm{C}$ before demiplug harvest (mosaicplasty followed by scalpel blade cut to split the plug centrally). Demiplugs were incubated at $21^{\circ} \mathrm{C}$ for 2 hours. (B) Representative projectional image, from one experiment $(n=3)$, from surface perspective, showing intersection of Acufex MP cut (curved) and scalpel cut (straight). White overlay = margin of live (green)/dead (red) cells. Blue overlay shows measurement of sector perimeter.

$76.7 \pm 0.99 \%$, respectively) than the $73.8 \pm 0.38 \%$ of Grade 0 (anterior and distal cuts pooled).

On excision from the bone, the change in wet weight of Grade 0 anterior cut tissue was not significantly different from zero (Table 1). However, distal cut Grade 0 tissue showed a small, but statistically significant $(\mathrm{P}=0.019)$ swelling of $1.68 \pm 0.39 \%$. For Grade 1 tissue there was no significant difference in swelling when tissues from the anterior and distal cuts were compared. Cartilage of Grades 1,2 , and 3 showed significant $(\mathrm{P}=0.0006, \mathrm{P}=0.0046$, $\mathrm{P}<0.0001$, respectively) swelling $(4.09 \pm 0.68 \%$, $5.31 \pm 1.50 \%$, and $11.7 \pm 1.67 \%$ respectively) compared with pooled Grade 0 tissue $(1.02 \pm 0.30 \%)$. The trend across grades was also significant (ANOVA; $\mathrm{P}<0.0001$ ).

Microscopic assessment of samples originally assigned Grade 1 was more variable. This suggested the surface zone was intact (as for Grade 0) in 4 (ex 12) samples, that 4 ex 12 had surface disruption only, and a final group (4 ex 12) had poorly-defined superficial zones with a defect that reached the middle zone. Analyses of these 3 subgroups by $t$-test and ANOVA did not show significant differences in terms of initial water content or swelling when excised from bone. Similarly in Grade 2 tissue there was heterogeneity in terms of the zones breached. In one sample, the defect did not reach the mid zone, in 4 ex 9 the mid zone was affected, and in a further 4 ex 9 the defect reached the deep zone. For Grade 3 tissue the defect reached the deep zone in all cases.
Table 2 shows cell distribution assessed using the descriptive ICRS histological score (Mainil-Varlet et al., 2003). Grade 0 tissue scored maximally with no clustering, and normal architecture. Unsurprisingly, with deteriorating grade there was a decline in columnar organisation with an increase in clustering (Fig. 5). Cell viability was $>95 \%$ in all sections.

\section{CLSM imaging of surgical incisions to cartilage}

Figure 6(A) shows how the cartilaginous portions of explants were incised with the Acufex MP and scalpel as far as the subchondral bone before gentle blade retraction. Samples were sectioned and imaged transversely. Figure

Table 2. Cartilage architecture - by ICRS grading.

\begin{tabular}{lllll} 
Score $/ /$ Grade $(n) \rightarrow$ & $0(12)$ & $1(13)$ & $2(9)$ & $3(5)$ \\
\hline 3 (columnar) & 12 & 10 & 2 & 0 \\
2 (mixed columnar/clusters) & 0 & 3 & 4 & 0 \\
1 (clusters) & 0 & 0 & 3 & 5 \\
0 (individual/disorganised) & 0 & 0 & 0 & 0
\end{tabular}

Tissue architecture was classified according to columnar/clustering pattern (Methods; Mainil-Varlet et al., 2003). There was increasing disorganisation and clustering as Grades increased from 0 to 3 (see Fig. 5). 
6(B,C) show representative projected images of incisions across the full depth of the cartilage with chondrocytes stained green (live) or red (dead). A common pattern was observed for all experiments $(n=3)$, the most extensive margin of death being for the Acufex MP in the superficial zone $(211 \pm 18.3 \mu \mathrm{m})$, substantially and significantly more than (1) the margin $(33.0 \pm 8.5 \mu \mathrm{m})$ associated with the scalpel cut $(\mathrm{P}=0.0009 ; n=3)$, and (2) the margin ( $50.5 \pm 13.6$ $\mu \mathrm{m})$ associated with the Acufex $M P$ cut in the mid-zone $(\mathrm{P}=0.0022 ; n=3)$. Quantitative analysis of the deep zones was not possible by the area-averaging method (see Methods; Chen et al., 2003), because of the low cell density.

Figure 7 shows (A) how plugs were harvested and then split longitudinally with a No. 11 blade to create demiplugs with two cut edges: (1) curved Acufex MP, and (2) straight scalpel cut, and (B) a representative projected image of vital-stained tissue at the intersection of the two cut-types, viewed from above $(n=3)$. In this unfixed tissue, the zone of cell death was $277 \pm 7.2 \mu$ m mean width for the Acufex, markedly greater $(\mathrm{P}<0.0001)$ than the $38.8 \pm 7.2$ $\mu \mathrm{m}$ associated with the scalpel cut.

\section{Discussion}

By comparing prospective macroscopic grading with the microscopic findings, we have shown the difficulties inherent in macroscopic grading of tissue (Noyes and Stabley, 1989; Bush and Hall, 2003). Microscopic verification is important even for ostensibly Grade 0 tissue, because 1 specimen (of the 13 originally graded 0 ) showed surface fibrillation on microscopy, and could therefore be excluded. The water content of $73.8 \pm 0.38 \%$ obtained for Grade 0 tissue compares well with the values obtained for (1) control femoral condylar and macroscopically nondegenerate tissue from osteoarthritis joint resections obtained in the key study of Brocklehurst et al. (1984), and (2) Grade 0 tissue from tibial plateau (Bush and Hall, 2003). Tissue hydration was increased for Grade 2 and 3 tissue, again consistent with previous studies (Brocklehurst et al., 2004; Bush and Hall, 2003), and taken as representing damage to the collagen network (Maroudas, 1976, 1990).

Swelling on excision from subchondral bone has previously been demonstrated for osteoarthritic human femoral condylar cartilage and is thought to be related to degeneration of the collagen network (Maroudas, 1990). Previous studies found that macroscopically nondegenerate cartilage from osteoarthritic femoral heads also swelled on excision, a phenomenon that was attributed to microdamage in the absence of gross focal changes (Maroudas, 1976; Grushko et al., 1989). However the situation was different for the femoral condyle, in which macroscopically non-degenerate tissue from osteoarthritic knees was not significantly different from control cartilage in terms of water content, proteoglycan content and chemistry, rate of sulphate incorporation and histology (Brocklehurst et al., 1984). Our study extends the findings of Brocklehurst et al. by measuring increased cartilage

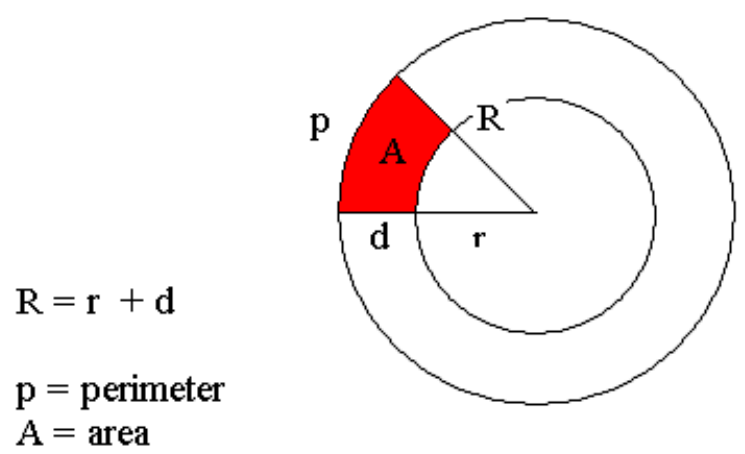

Figure 8. Model of osteochondral cylinder articular surface. The margin of cell death, is represented by the area bounded by the perimeters of the concentric circles of radius $\mathbf{r}$ and $\mathbf{R}$ respectively.

swelling on excision, according to grade. A subset analysis of Grade 0 lateral condylar tissue, according to its anatomical origin (anterior or distal cut), showed (1) no significant swelling for tissue from the anterior cut, and (2) a difference for distal cut tissue (which is from a higher demand region of the joint) compared with anterior cut, in that there was a significant propensity to swell, albeit by only $1.68 \pm 0.39 \%$ (Table 1 ).

Grading is subjective, and carries many reservations (Noyes and Stabler, 1989). However our approach to identify non-degenerate tissue, involving an initial visual inspection and further exclusion after confocal laser scanning microscopy (CLSM) (Bush and Hall, 2003) from a transverse perspective (as for the 'Structure' component of the Mankin score (Mankin et al., 1971) - see Fig. 5), allowed selection of tissue that had normal biophysical hydration parameters. For analysis of the effects of harvest techniques on non-degenerate tissue, we therefore advocate the use of (1) the anterior cut only as a source of explants, and (2) microscopy from the transverse perspective to exclude samples that appear normal macroscopically but are surface-fibrillated.

Data concerning cell death associated with full thickness cartilage cuts show that early death ( 2 hours postcut) due to the Acufex MP is substantially greater in the superficial zone (SZ) than the mid zone, and also greater than that associated with a scalpel cut to the same level (Fig. 6). Death does not occur merely because of tissue incision because it was minimal at the scalpel cut.

It seems likely that blade geometry is critical, especially parameters such as sharpness, the angle subtended at the cutting-tip, nature of internal and external bevels, blade thickness, and blade face roughness (Huntley, 2004). Cutting using the Acufex MP (Fig. 4) must subject the cartilage to a variety of deforming forces, including compression, shear and abrasion. How this form of mechanical trauma interacts with the SZ to cause such a substantial zone of death is not clear. Anecdotally, it is the surgeon's observation that for a given blade, more force is required to cut the superficial zone than the deeper zones.

Interestingly, the $\mathrm{SZ}$ of adult bovine cartilage is similarly vulnerable, when subjected to 1-5 MPa cyclical sinusoidal confined compression (Chen et al., 2003). 
Collagenase-cleaved and denatured collagen fibres colocalised to this layer. Again the nature of the mechanical trauma experienced by the chondrocytes and how this leads to early cell death is unclear. However, Chen et al. note that the confined compression modulus of full thickness bovine articular cartilage is depth-dependent (Schinagl et al., 1997), with the SZ having the lowest compressive modulus. The important and intimate association between chondrocytes and their extracellular matrix has been emphasised previously eg in the formation of focal adhesion plaques at the sites of chondrocyte integrin binding to ECM molecules (Muir, 1995; Van der Kraan et al., 2002 and references therein). Our results document cell death using propidium iodide at 2 hours post cutting, a time frame that would tend to preclude an apoptotic mechanism (Chen et al., 2003), notwithstanding the later importance of this process to a secondary wave of death in wounded cartilage (Tew et al., 2000; Redman et al., 2004). In the context of osteochondral grafting, SZ death is important because the matrix is dependent on the chondrocytes for remodelling/integration, and the superficial zone has a fundamental role within articular cartilage (Korhonen et al., 2002) as the tension-retaining diaphragm (Meachim and Stockwell, 1973), tissue- and hydraulic permeability- limiting (Maroudas, 1976), and the site of chondroprogenitor stem cells (Dowthwaite et al., 2004).

One reservation concerning our model is the effect of age. Unsurprisingly, the bone-cartilage composite tissue used in this study was more aged (mean 68.4 years) than would be found suitable for mosaicplasty (patients $<35$ years; Hangody et al., 2004). Articular cartilage undergoes certain biochemical and structural changes with age, including changes in proteoglycan composition, collagen cross-linking, tensile strength and stiffness (Stockwell, 1979; Buckwalter and Mankin 1997a,b; Martin and Buckwalter, 2003). However it is unknown whether age has an effect on the sensitivity of articular cartilage to surgical trauma. A further reservation, and one which applies equally to clinical osteochondral autografting, concerns the use of the 'lower demand' (decreased loadbearing) portion of the joint. This region may have different biomechanical and reparative properties compared to the higher demand areas.

Mankin et al. (1971) commented on the apparently focal nature of osteoarthritis at the knee. Brocklehurst et al. (1984) compared the chemical properties of macroscopically non-degenerate tissue from osteoarthritic knees with control condylar tissue and could demonstrate no difference in histology, metabolism or biochemistry. They inferred that visually intact cartilage from an osteoarthritic knee was functionally normal, supporting the contention that unicompartmental arthroplasty with mechanical axis correction was a reasonable alternative to total knee arthroplasty.

Working on isolated, cultured chondrocytes, MillwardSadler et al. (1998) showed that cells isolated from macroscopically normal cartilage of osteoarthritic joints hyperpolarised in response to cyclical pressure-induced strain, in a manner analagous to chondrocytes from normal cartilage and in contradistinction to chondrocytes isolated from a degenerate area - which had a depolarisation response.

These experimental findings (Brocklehurst et al., 1984; Millward-Sadler et al., 1998) suggest that, to a certain extent, knee osteoarthritis may be regarded as a focal as opposed to a pan-joint condition. This broadly supports the contention that macroscopically non-degenerate tissue from the osteoarthritic joint is of similar nature to healthy human cartilage.

Confocal laser scanning microscopy (CLSM) has proved capable of following the magnitude of early cell death in association with different types of surgical cut, from both surface and transverse perspectives. Cells can be visualised in three dimensions within their natural ECM, and quantitative analysis of dead-living cells in relation to cuts is possible in both fixed (Figs 5,6) and unfixed (Fig. 7) tissue. The relevance of this latter observation is that a region of interest can potentially be followed over time, which should allow assessment of the early dynamics of cell death.

In summary, we have developed a human model osteochondral system and mode of analysis (Fig. 8, appendix), for assessment of cartilage surgery. Analysis of femoral condylar tissue suggests that macroscopically non-degenerate (if microscopically checked) lateral condylar explants from anterior cuts at knee arthroplasty for osteoarthritis yields tissue that approximates to normal cartilage in biophysical terms, and can therefore reasonably be used to assess the effects of surgical trauma.

Using this model, we have demonstrated that Acufex $M P$ cutting, as for mosaicplasty, causes (1) a substantially greater margin of cell death than a fresh scalpel blade, and (2) proportionately more cell death in the superficial zone. This effect is important because of the fundamental role of this zone in the overall structural/functional topography of articular cartilage. Because of its human origin, we believe this model represents an important addition to the techniques available for the assessment of osteochondral surgery.

\section{Appendix}

Osteochondral harvest currently involves obtaining bonecartilage cylinders. The CLSM system described here penetrates tissue to $170 \mu \mathrm{m}$. Hence if the Grade 0 articular surface is imaged from above, only the superficial zone is assessed. We have argued the prime importance of the superficial zone in repair/reconstruction (Discussion). It is desirable to use a single variable to define the marginal zone of death. For an osteochondral cylinder of any defined diameter it seems reasonable to define the zone of cell death in terms of a mean margin (d; $\mathrm{mm})$.

Consider two concentric circles, having radii $\mathrm{r}$ and $\mathrm{R}$ (Fig. 8), such that $\mathbf{R}=\mathbf{r}+\mathbf{d}$, in which the circle of radius $\mathbf{R}$ represents the surface of the osteochondral graft, and the circle of radius $\mathbf{r}$ represents the viable area.

Using image analysis (such as the Zeiss Browser), the perimeter of a sector of plug can be measured, as can the 
area (A) - being the area of cell death bounded by the perimeter line (p) and two perpendiculars dropped from the ends of the perimeter line. The inner boundary of the area $\mathbf{A}$ is given by the live/dead border.

Defining the area $\mathbf{A}$ :

$$
\begin{aligned}
\mathbf{A} & =(\mathbf{p} / 2 \pi \mathbf{R})\left(\pi \mathbf{R}^{2}-\pi \mathbf{r}^{2}\right) \\
& =(\mathbf{p} / 2 \mathbf{R})\left(\mathbf{R}^{2}-\mathbf{r}^{2}\right)
\end{aligned}
$$

Re-arranging to find $\mathbf{r}$ :

$$
\begin{aligned}
& \mathbf{r}^{2}=\mathbf{R}^{2}-2 \mathbf{R A} / \mathbf{p} \\
& \mathbf{r}=\sqrt{ }\left\{\mathbf{R}^{2}-2 \mathbf{R A} / \mathbf{p}\right\}
\end{aligned}
$$

Substituting for $\mathbf{r}$ (= R-d), and re-arranging for $\mathbf{d}$ :

$$
\mathbf{d}=\mathbf{R}-\sqrt{ }\left\{\mathbf{R}^{2}-2 \mathbf{R A} / \mathbf{p}\right\}
$$

Using this formula, the margin of death $\mathbf{d}$, can be calculated from the measured values $\mathbf{R}, \mathbf{A}$ and $\mathbf{p}$.

\section{Acknowledgements}

We thank Mr IJ Brenkel (Fife Acute Hospitals) for providing the knee resection specimens. We are grateful to Smith \& Nephew for providing the mosaicplasty harvest kits free of charge. This project was supported by Wellcome Trust funding (045925/Z/95/A).

\section{References}

Ahsan T, Sah RL (1999) Biomechanics of integrative cartilage repair. Osteoarthritis Cartilage 7: 29-40.

Aubin PP, Cheah HK, Davis AM, Gross AE (2001) Long-term followup of fresh osteochondral allografts for posttraumatic knee defects. Clin Orth 391S: S318-S327.

Bentley G, Biant LC, Carrington RWJ, Akmal M, Goldberg A, Williams AM, Skinner JA, Pringle J (2003) A prospective, randomised comparison of autologous chondrocyte implantation versus mosaicplasty for osteochondral defects in the knee. J Bone Joint Surg 85B: 223-230.

Bos PK, DeGroot J, Buddle M, Verhaar JA, van Osch GJ (2002) Specific enzymatic treatment of bovine and human articular cartilage: implications for integrative cartilage repair. Arthritis Rheum 46: 976-985.

Brocklehurst R, Bayliss MT, Maroudas A, Coysh HL, Freeman MAR, Revell PA, Ali SY (1984). The composition of normal and osteoarthritic articular cartilage from human knee joints. With special reference to unicompartmental replacement and osteotomy of the knee. J Bone Joint Surg 66A: 95-106.

Buckwalter JA, Mankin HJ (1997a) Articular cartilage. Part I. Tissue design and chondrocyte-matrix interactions. J Bone Joint Surg 79A: 600-611.

Buckwalter JA, Mankin HJ (1997b) Articular cartilage. Part II. Degeneration and osteoarthrosis, repair, regeneration, and transplantation. J Bone Joint Surg 79A: 612-632.

Bush PG, Hall AC (2003) The volume and morphology of chondrocytes within non-degenerate and degenerate human articular cartilage. Osteoarthritis Cartilage 11: 242251.

Chen CT, Bhargava M, Lin PM, Torzilli PA (2003) Time, stress, and location dependent chondrocyte death and collagen damage in cylically loaded articular cartilage. J Orthop Res 21: 888-898.

Collins DH (1949) The Pathology of Articular and Spinal Diseases. Arnold, London.

Collins DH, McElligott (1960) Sulphate $\left({ }^{35} \mathrm{SO}_{4}\right)$ uptake by chondrocytes in relation to histological changes in osteoarthritic human articular cartilage. Ann Rheum Dis 19: $318-330$.

Czitrom AA, Keating S, Gross AE (1990) The viability of articular cartilage in fresh osteochondral allografts. J Bone Joint Surg 72A: 574-581.

DiMicco MA, Sah RL (2001) Integrative cartilage repair: adhesive strength is correlated with collagen deposition. J Orthopaed Res 19: 1105-1112.

Dowthwaite GP, Bishop JC, Redman SN, Khan IM, Rooney P, Evans DJ, Haughton L, Bayram Z, Boyer S, Thomson B, Wolfe MS, Archer CW (2004) The surface of articular cartilage contains a progenitor cell population. $\mathrm{J}$ Cell Sci 117:889-897.

Engh GA (2000) Orienting the femoral component at total knee arthroplasty. Am J Knee Surg 13: 162-165.

Evans PJ, Miniaci A, Hurtig MB (2004) Manual punch versus power harvesting of osteochondral grafts. Arthroscopy 20: 306-310.

Grushko G, Schneiderman R, Maroudas A(1989) Some biochemical and biophysical parameters for the study of the pathogenesis of osteoarthritis: a comparison between the processes of ageing and degeneration in human hip cartilage. Conn Tiss Res 19: 149-176.

Hangody L, Fules P (2003) Autologous osteochondral mosaicplasty for the treatment of full-thickness defects of weight-bearing joints. J Bone Joint Surg 85A(Suppl 2): 25-32.

Hangody L, Rathonyi GK, Duska Z, Vasarhelyi G, Fules P, Modis L (2004) Autologous osteochondral mosaicplasty. J Bone Joint Surg 86A(Suppl 1): 65-72.

Horas U, Pelinkovic D, Herr G, Aigner T, Schnettler R (2003) Autologous chondrocyte implantation and osteochondral cylinder transplantation in cartilage repair of the knee joint. J Bone Joint Surg 85A:185-92.

Hulet C, Sabatier JP, Souquet D, Locker B, Marcelli C, Vielpeau C (2002) Distribution of bone mineral density at the proximal tibia in knee osteoarthritis. Calcif Tissue Int 71: 315-322.

Huntley JS (2004) Cutting cartilage - surgical perspective. Osteoarthritis Cartilage 12: 846-847.

Hunziker EB (2001) Articular cartilage repair: basic science and clinical progress. A review of the current status and prospects. Osteoarthritis Cartilage 10: 432-463.

Hunziker EB, Quinn TM (2003) Surgical removal of articular cartilage leads to loss of chondrocytes from cartilage bordering the wound edge. J Bone Joint Surg 85A: 85-92. 
Jeffery AK, Blunn GW, Archer CW, Bentley G (1991) Three-dimensional collagen architecture in bovine articular cartilage. J Bone Joint Surg 73B: 795-801.

Korhonen RK, Wong M, Arokoski J, Lindgren R, Helminen HJ, Hunziker EB, Jurvelin JS (2002) Importance of the superficial tissue layer for the indentation stiffness of articular cartilage. Med Eng Phys 24: 99-108.

Lexer E (1908) Substitution of whole or half joints from freshly amputated extremities by free plastic operation. Surg Gynaecol Obstet 6: 601-607 [reprinted 1985. The Classic. Joint Transplantation. By Eric Lexer. 1908. Clin Orthop 197: 4-10].

Lexer E (1925) Joint transplantations and arthroplasty. Surg Gynecol Obstet 40: 782-809.

Mainil-Varlet P, Monin D, Weiler C, Grogan S, Schaffner T, Zuger B, Frenz M (2001) Quantification of laser-induced cartilage injury by confocal microscopy in an ex vivo model. J Bone Joint Surg 83A: 566-571.

Mainil-Varlet P, Aigner T, Brittberg M, Bullough P, Hollander A, Hunziker E, Kandel R, Nehrer S, Pritzker K, Roberts S, Stauffer E (2003) Histological assessment of cartilage repair. A report by the histology endpoint committee of the international cartilage repair society (ICRS). J Bone Joint Surg 85A: 45-57.

Mankin HJ, Dorfman H, Lippiello L, Zarins A (1971) Biochemical and metabolic abnormalities in articular cartilage from osteo-arthritic human hips. II. Correlation of morphology with biochemical and metabolic data. J Bone Joint Surg 53A: 523-537.

Maroudas AI (1976) Balance between swelling pressure and collagen tension in normal and degenerate cartilage. Nature 260: 808-809.

Maroudas A (1990) Tissue Composition and Organisation. In: Methods in Connective Tissue Research (Maroudas A, Kuettner K, eds). Chapter 9. Academic Press, London.

Martin JA, Buckwalter JA (2002) Aging, articular cartilage chondrocyte senescence and osteoarthritis. Biogerontology 3: 257-264.

Meachim G, Stockwell RA (1973) The Matrix. In: Adult Articular Cartilage (Freeman MAR, ed). Chapter 1. Pitman Medical, London.

Millward-Sadler SJ, Wright MO, Nuki G, Salter DM (1998) Chondrocytes from osteoarthritic cartilage show an altered electrophysiological response to mechanical stimulation. J Pathol 184S:34A (abstr).

Mitchell N, Shepard N (1989) The deleterious effects of drying on articular cartilage. J Bone Joint Surg 71A: 89-95.
Muir H (1995) The chondrocyte, architect of cartilage. Bioessays 17:1039-1048.

Nicholson R (2004) Divergent standards for consent in research. Bull Med Eth 194:13-24.

Noyes FR, Stabler CL (1989) A system for grading articular cartilage lesions at arthroscopy. Am J Sports Med 17: 505-513.

Poole AR (2003) What type of cartilage repair are we attempting to obtain? J Bone Joint Surg 85A: 40-44.

Redman SN, Dowthwaite GP, Thomson BM, Archer CW (2004) The cellular responses of articular cartilage to sharp and blunt trauma. Osteoarthritis Cartilage 12: 106116.

Reindel ES, Ayroso AM, Chen AC, Chun DM, Schinagl RM, Sah RL (1995) Integrative repair of articular cartilage in vitro: adhesive strength of the interface region. J Orthop Res 13: 751-760.

Roach HI, Shearer JR, Archer C (1989) The choice of an experimental model. A guide for research workers. J Bone Joint Surg 71B: 549-553.

Scuderi GR, Insall JN (2000) Rotational positioning of the femoral component in total knee arthroplasty. Am J Knee Surg 13: 159-161.

Schinagl RM, Gurskis D, Chen AC, Sah RL (1997) Depth-dependent confined compression modulus of fullthickness bovine articular cartilage. J Orthop Res 15: 499506.

Shapiro F, Koide S, Glimcher MJ (1993) Cell origin and differentiation in the repair of full-thickness defects of articular cartilage. J Bone Joint Surg 75A: 532-553.

Stockwell RA (1979) Biology of cartilage cells. Cambridge University Press

Tew SR, Kwan AP, Hann A, Thomson B, Archer CW (2000) The reactions of articular cartilage to experimental wounding: role of apoptosis. Arthritis Rheum 43: 215-225.

Van der Kraan PM, Buma P, van Kuppevelt T, van den Berg WB (2002) Interaction of chondrocytes, extracellular matrix and growth factors: relevance for articular cartilage tissue engineering. Osteoarthritis Cartilage 10: 631-637

Volkov M (1970) Allotransplantation of joints. J Bone Joint Surg Br 52B: 49-53.

\section{Web Reference}

ICRS (2000) http://www.cartilage.org/files/ ICRS_evaluation.pdf [accessed 14/06/04] 